\title{
Phonological and neuroanatomical findings in three cases with apraxia of speech ${ }^{*}$
}

\author{
Lesley Wolk MA (Speech Pathology) (Witwatersrand) \\ Department of Speech Pathology, and Audiology, \\ University of the Witwatersrand, Johannesburg
}

\begin{abstract}
This study investigated whether or not the articulatory errors on single consonants and initial consonant clusters in three adult aphasic patients with apraxia of speech could be characterized by underlying phonological processes. Naming tasks and spontaneous narrative tasks were used for elicitation of speech samples. Computerized tomography was carried out in order to deter mine possible neuroanatomical correlates of the linguistic findings in these cases. Results revealed that in each case, it was possible to trace underlying phonological processes which:fit into strategy groups operationalizing particular phonetic preferences. Similar trends occurred on all tasks. Self-employed strategies to aid phonological production were used by all cases during their struggle with successive attempts towards the target utterance. Neuroanatomical findings demonstrated brain lesions which were more extensive than would be expected in the traditional concept of a focal lesion in Broca's area. In each case the left parietal region was involved. Theoretical and clinical implications are discussed.
\end{abstract}

\section{OPSOMMING}

Hierdie studie ondersoek die moontlikheid dat onderliggende fonologiese prosesse die artikulasie foute (enkel konsonante en inisiële konsonant kombinasie) van drie afasie pasiënte met verbale apraksie kan karakteriseer word. Benoemingstake en spontane verhalende spraak is gebruik om spraakmonsters te ontlok. Gerekenariseerde tomografisie is onderneem om moontlik neuroanatomiese korrelate van linguistiese bevindings in hierdie gevalle te bepaal. Resultate dui daarop dat dit in elke geval moontlik was om onderliggende fonologiese prosesse uit te wys. Hierdie prosesse kon ingedeel word in groepe wat spesifieke fonetiese voorkeur verleen t.o.v. strategie soortgelyke neigings het in al die take voorgekom. Selftoegepaste strategieë om fonologiese produksie te bevorder, is deur alle pasiënte gebruik tydens hulle worsteling met opeenvolgende pogings tot die teiken uiting. Neuroanatomise bevindings het getoon dat brein letsels groter was as wat verwag word van die tradisionele konsep van 'n fokaleletsel van Broca se area. In elke pasiënt, was die linkse pariëtale area betrokke by die letsel. Teoretiese en kliniese implikasies is bespre'ek.

Recent research into the area of aphasia has witnessed a surge of interest in articulatory disturbances, particularly in Broca's aphasic patients. Multiple terms have been employed to describe the articulatory impairment; for consistency in this paper, the term 'apraxia of speech' will be used. The investigation of apraxia of speech in this study extracts from linguistic approaches and neurological methods of investigation.

Apraxia of speech is both controversial and complex despite many years of research. Several investigators have described the disorder as a motor programming disturbance not primarily due to neuromuscular or higher language functioning deficits, and have suggested that the programming of phonemes can be selectively impaired without impairment of language (Deal and Darley, 1972). Martin (1974), however, objected to the term 'apraxia of speech' and argued that motor programming disturbances are inextricably tied to language deficits and cannot be defined except within the framework of aphasia.
Controversy has further ensued regarding the nature of articulatory impairment. Some investigators have argued that articulation errors are random and unrelated to the target sound (Critchley, 1952; Deal and Darley, 1972) while others have concluded that errors are systematic and rule-governed (Blumstein, 1973; Martin and Rigrodsky, 1974a; 1974b; Klich, Ireland and Weidner, 1979). The development of apparent incompatible conceptions of the disorder is due, at least in part, to the phenomenon itself. In addition, guidelines for treatment have been somewhat fragmentary and meagre.

Numerous workers in the field of adult apraxic disorders have extrapolated from child language in an attempt to unravel some of the conceptual controversies discussed and to design effective treatment programmes. There may be several limitations of this procedure, for example that of over-simplifying the adult aphasic breakdown. Yet, the knowledge acquired through extrapolating from child language has contributed in some way

* This study formed part of the author's MA dissertation entitled "Phonological Impairment in Aphasia" submitted to the Department of Speech Puthology and Audiology, University of the Witwatersrand, Johannesburg. 
to the understanding of these cases and to the overall clinical management. Research on distinctive feature analyses in patients with apraxia of speech suggests that error productions are systematically related to their target sounds in terms of a feature breakdown (Martin and Rigrodsky, 1974a; 1974b). There has been limited application of phonological process analyses (Bowman, 1982). Phonological processes, as they are described in child language, refer to general simplifying processes that affect entire classes of sounds (Ingram, 1976). They do not reflect random errors, rather they are said to result from a set of systematic strategies operationalizing a child's phonetic preferences (Ingram, 1976; 1981). It has been argued that the phonological processes may provide the general patterns that need to be eliminated in therapy, and that if trained on key sounds, generalization is likely to occur (Weiner, 1979).

Cohen, Gelfer and Sweet (1980) feel that it is essential for the clinician to evaluate the aphasic patient's speech performance and to compare this with the anatomical localization afforded by computerized tomography (CT). Buckingham (1979) further argues that it is difficult to determine what constitutes an apraxia of speech without further specifying the location of. the lesion and the stimulus conditions which evoked the behaviour said to be apraxic.

Thus the primary goal of this study was to investigate whether the articulatory errors on single consonants and initial con- sonant clusters in three adult aphasic patients with apraxia of speech could be characterized by underlying phonological processes, considering which ones operate most commonly; a secondary goal was to describe CT scan findings in these cases. These findings are discussed briefly in a recent report (Wolk, 1982a).

\section{METHOD}

\section{SUBJECTS}

Three adult male aphasic patients were used as subjects for this study. All cases were chosen from Johannesburg hospitals and were diagnosed as aphasic by neurologists and speech pathologists. They ranged from age 58 to 73 years with a mean age of 63,3 years. All cases presented a history of left $(\mathrm{L})$ hemisphere cerebrovascular accident (CVA). They demonstrated various degree of concomitant Broca's aphasia. In each case, however, phonological deficit predominated. They ranged in months post onset (MPO) from 9 to 24, with a mean of 15,7 months. All cases were native speakers of English and had no previous history of speech or hearing problems, premorbid psychological problems, senility or mental retardation. Years of education ranged from 8 to 11 with a mean of 9,7 years. Case 1 had the most severe form of apraxia of speech, and Case 3 the least severe disorder. Subjects had to have suffered a left (L) cerebral infarct, and were required to have reached a point

Table 1 Description of cases

\begin{tabular}{|c|c|c|c|c|c|c|c|c|c|c|}
\hline & Age & Sex & Aetiology & $\begin{array}{c}\text { Months } \\
\text { Post Onset } \\
\text { MPO }\end{array}$ & $\begin{array}{c}\text { Type } \\
\text { of } \\
\text { Aphasia }\end{array}$ & $\begin{array}{c}\text { Home } \\
\text { Language }\end{array}$ & $\begin{array}{c}\text { Educational } \\
\text { Level }\end{array}$ & $\begin{array}{l}\text { Premorbid } \\
\text { Occupation }\end{array}$ & $\begin{array}{l}\text { Handed- } \\
\text { ness }\end{array}$ & $\begin{array}{l}\text { Speech } \\
\text { Therapy } \\
\text { Received }\end{array}$ \\
\hline $\begin{array}{l}\text { Case } 1 \\
\text { (A.M.) }\end{array}$ & 58 & Male & CVA & 24 & Broca & English & Std. 6 & Plumber & (R) & 18 months \\
\hline $\begin{array}{c}\text { Case } 2 \\
\text { (FT:) }\end{array}$ & 73 & Male & CVA & 9 & Broca & English & Std. 8 & $\begin{array}{l}\text { Despatch } \\
\text { Manager }\end{array}$ & (R) & 4 months \\
\hline $\begin{array}{c}\text { Ć́ase } 3 \\
\text { (E.J.) }\end{array}$ & 59 & Male & CVA & 14 & Broca & English & Std. 9 & Salesman & (R) & 12 months \\
\hline
\end{tabular}

Table 2 Results of Preliminary Tests

\begin{tabular}{|c|c|c|c|}
\hline Preliminary Test & $\begin{array}{l}\text { Case } 1 \\
\text { (A.M.) }\end{array}$ & $\begin{array}{l}\text { Case } 2 \\
\text { (F.T.) }\end{array}$ & $\begin{array}{l}\text { Case } 3 \\
\text { (E.J.) }\end{array}$ \\
\hline $\begin{array}{l}\text { Boston Diagnostic Aphasia Examination (BDAE) } \\
\text { Goodglass and Kaplan (1972) }\end{array}$ & $\begin{array}{l}\text { Score on severity } \\
\text { rating scale }=2\end{array}$ & $\begin{array}{l}\text { Score on severity } \\
\text { rating scale }=2\end{array}$ & \multirow{2}{*}{$\begin{array}{l}\text { Score on severity } \\
\text { rating scale }=2 \\
36 / 36=100 \%\end{array}$} \\
\hline $\begin{array}{l}\text { Token Test } \\
\text { De Renzi and Faglioni (1978) }\end{array}$ & $34 / 36=94 \%$ & $34 / 36=94 \%$ & \\
\hline $\begin{array}{l}\text { Oral Non-verbal Gesture Battery } \\
\text { Moore, Rosenbek \& La Pointe (1976) }\end{array}$ & $56 / 56=100 \%$ & $56 / 56=100 \%$ & $56 / 56=100 \%$ \\
\hline Screening Pure-Tone Audiometric Test & Normal & $\begin{array}{l}\text { Normal except } 45 \mathrm{~dB} \\
\text { at } 4000 \mathrm{~Hz} \text { bilaterally }\end{array}$ & Normal \\
\hline $\begin{array}{l}\text { Goldman-Fristoe Test of Auditory Discrimination } \\
\text { (Goldman, Fristoe and Woodcock, 1970) }\end{array}$ & $100 \%$ & $100 \%$ & $100 \%$ \\
\hline Discrimination of CVC and CCVC words (designed by the writer) & $100 \%$ & $100 \%$ & $100 \%$ \\
\hline
\end{tabular}


of neurological stability considered as six months after the neurological insult (Sarno and Levita, 1971). The description of cases is summarized in Table 1.

\section{PROCEDURE}

Preliminary tests were carried out to determine whether the subjects satisfied the selection criteria. These are summarized in Table 2.

Two approaches were used for elicitation of speech for linguistic analysis:-

(1) Naming Tasks and (2) Spontaneous Narrative Tasks.

\section{Naming tasks}

A test comprising two parts was developed by the writer for use in this study. Part I was designed to test single consonants in initial (I) and final (F) word position, and Part II was designed to test initial consonant cluster sequences.

\section{Criteria for Selection of Words}

Part I of the articulatory test was composed of 89 items, carefully selected to elicit all the consonants (C) in English in (I) and (F) word positions. An attempt was made to select items in which the desired consonant in (I) and (F) word position could be elicited simultaneously, thus maximally conserving the total number of picture stimuli required (for example, initial /d/ is elicited by the picture words 'dog' and 'duck' at the same time that final $/ g /$ and $/ \mathrm{k} /$ are being elicited). Each consonant was elicited at least twice in (I) and (F) word position, ranging between two and four different phonemic contexts. The phonemic environment was varied with respect to both vowels and consonants in the immediate phonemic vicinity. Thus 81 words represented consonants in (I) position, and 70 words represented consonants in (F) position, while the total number of test items was equal to 89 .

Part II of the articulatory test was composed of 99 items. Each (I) cluster of English was elicited in at least two stimulus words, ranging between two and four different phonemic contexts.

\section{Experimental Manipulation of Words}

Stimulus items were constrained by the following:' i) phonological rules governing the combination and sequencing of phonemes in English; ii) words which could be pictorially represented, for the reason that imitation was to be deliberately avoided; iii) word length and syllable structure were considered - mono syllabic and disyllabic words were included, while multisyllabic words were excluded; iv) morphological endings were excluded when devising the list of single consonants in (F) position so as to elicit 'pure phonological constructions'.

The entire articulatory test thus comprised 188 stimulus items (Part I = 89; Part II = 99). Each response was elicited twice, to provide an estimate of the subjects' consistency of production of the same sounds in identical environments. Thus both parts of the naming task, naming singletons (NS) and naming clusters (NC) were administered twice to all subjects.

\section{Spontaneous narrative tasks}

These included an open-ended conversation, description of fifty pictures and constructing a story from six pictures depicting real-life scenes.

\section{ADMINISTRATION OF PHONOLOGICAL ASSESSMENT} PROCEDURE

All testing took place in a sound-treated room and was carried out by the writer during several 45 -minute sessions. Subjects were tested individually.

For the naming tasks, pictures were presented in a random order, but attempts were made not to present two words with the same consonant or consonant cluster successively. Part I (NS) and Part II (NC) were administered twice over four sessions, following the same procedure. For the spontaneous tasks, each subject had to describe the fifty picture cards selected and to tell a story for each of the six picture cards chosen. Spontaneous narrative tasks were administered once over three or four sessions.

\section{RESPONSE TRANSCRIPTION}

All responses were recorded on a high quality Revox Tape Recorder (Model 1132 Dolby version). Wherever possible onsite transcriptions were carried out by the writer, utilizing both visual cues and contextual information. Tape recordings were transcribed by the tester in broad phonetic transcriptions, and were used as a comparison with on-site transcriptions. A second transcription of all data was carried out using three transcribers who served as judges. Judges worked independently and then met jointly to resolve any discrepancies, discarding any instances in which no consensus could be reached, providing maximum objectivity and accuracy of recorded data.

\section{PHONOLOGICAL PROCESS ANALYSIS}

The goal was to discover whether articulation errors of these subjects could be characterized by general processes, and if so, which phonological processes were operating for each case. All CVC and CCVC words with error productions were analyzed in terms of one or more of the following broad categories as described by Weiner (1979): a) syllable structure processes, b) harmony processes and c) feature contrast processes. Within these categories, several specific phonological processes were selected from those described in child language (Ingram, 1976; 1981; Weiner, 1979).

It was possible that multiple processes could occur at the same time for a particular error utterance, in which case credit was given to as many processes as were operating for that utterance. In this way it was possible to determine the frequency of occurrence of each process and its probable resulting effect on intelligibility. The same procedure was carried out for both naming and spontaneous tasks for each case.

\section{ASSESSMENT PROCEDURE FOR NEUROLOGICAL INVESTIGATION}

Neuroanatomical investigations of the cases in this study included general neurological examinations carried out by the same neurologist, and computerized tomography (CT) scans for each case. CT' scans were performed with contrast enhancement on the Elscint 905 system. CT scan pictures obtained from the assessment procedure for the cases of this study were interpreted by a radiologist and two independent neurologists in order to provide a measure of objectivity and reliability.

The Soush African Joumal of Communication Disorders, Vol. 31, 1984 


\section{RESULTS AND DISCUSSION}

\section{PHONOLOGICAL FINDINGS}

Table 3 represents a summary of the phonological processes operating for all cases. The findings indicate that in each case certain phonological processes occurred more frequently than others, and that these occurred in similar proportions on both naming and spontaneous tasks. The findings will be discussed below in terms of three broad categories, i.e. syllable structure processes, harmony processes and feature contrast processes.

\section{Syllable Striciure Processes}

The three most commonly used syllable structure processes for all cases, were deletion of final consonant, weak syllable deletion and cluster reduction. Cluster reduction was the most commonly operating phonological process on naming tasks for all cases. It was necessary to develop a subcategory of the cluster reduction process to indicate that it was possible for an error substitution to reflect an extraction of select features of one or more elements of the target segment which merge together to form a new segment. This was referred to as 'feature merging'. Feature merging comprised a substantial num- ber of errors, for example in the case of A.M., $27,64 \%$ and $34,48 \%$ of cluster reduction errors were seen to occur on naming and spontaneous tasks respectively. An example of feature merging is clearly illustrated in the error substitution $/ \mathrm{sp} /$ for the target segment /skw/ which occurred in Cases 1 and 3 . Here it can be noted that /s/ remains the same, /p/ retains the plosive quality of $C_{2}$ but acquires the labial quality of $C_{3}$ in the target segment.

A review of the data indicated that there was a frequent collapse of 2-element and 3-element cluster segments into one element in all cases. In A.M.'s system, the sound preference or neutralization process (Weiner, 1979) was /// as in $/ / \mathrm{sl}$, //sk, j/spl, [r/skw. In F.T.s system, there were two sound preferences, $/ / /$ and $/ \mathrm{f} /$ as in $/ / \mathrm{skw}, \mathrm{j} / \mathrm{str}, \mathrm{f} / \mathrm{skw}, \mathrm{f} / \mathrm{spl}, \mathrm{f} / \mathrm{bl}, \mathrm{f} / \mathrm{gr}, \mathrm{fr} / \mathrm{skw}, \mathrm{fl} / \mathrm{spr}$. In E.J.'s system there were three sound preferences $/ / /$, /f/ and /s/ as in $1 / \mathrm{str}, \mathrm{j} / \mathrm{skw}, \mathrm{f} / \mathrm{jr}, \mathrm{f} / \mathrm{kw}, \mathrm{s} / \Theta \mathrm{r}, \mathrm{s} / \mathrm{fr} \mathrm{s} / \mathrm{tw}$. Therefore the blade-palatal fricative / / was a favourite sound strategy in all cases, the labiodental fricative /f/ was common to F.T. and E.J., and the tip-alveolar fricative /s/ was an additional favourite sound strategy in E.J.'s system.

The processes of reduplication, cluster contraction and epenthesis were operating in all cases, although less commonly

Table 3 A distribution of errors on CVC and CCVC words according to phonological processes

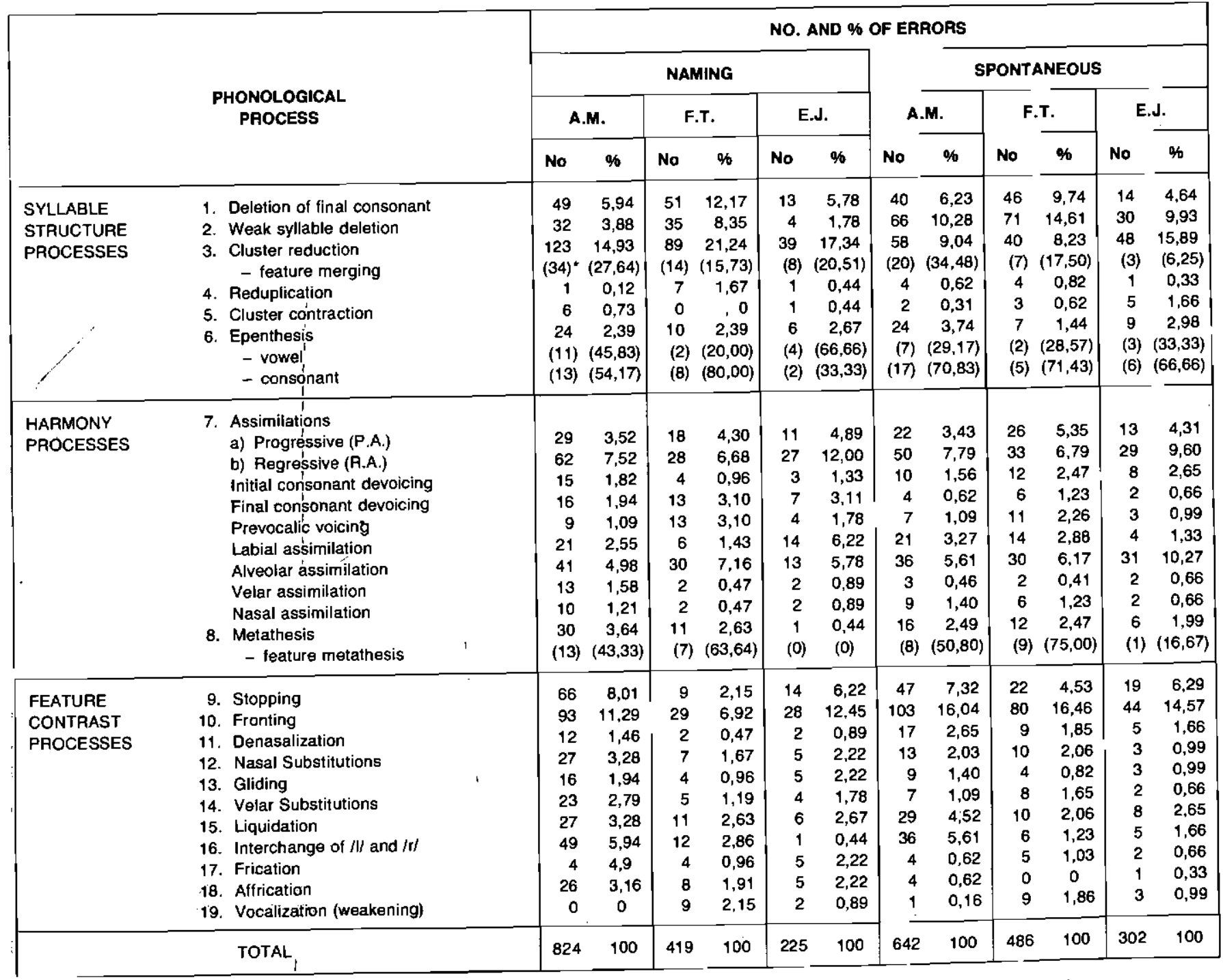

"Those numbersienclosed between brackets are sub-divisions of major categories and are therefore not included in the totals of each column. 
than those processes discussed above. Reduplication reflects the patients' awareness of the number of syllables in a given word, though he may not have the ability to produce the variety of syllables in sequence. For epenthesis in all cases, the insertion of a consonant was usually slightly more common than the insertion of a vowel for both tasks. An observation of the data showed that in vowel epenthesis, the vowel most commonly used in all cases was the mid schwa /a/, whilst in consonant epenthesis, A.M. used nasals, stops and liquids, F.T. and E.J. used nasals, stops, liquids and fricatives. Cluster contraction was used less commonly. An observation of the data showed that when it was employed however, it was more likely to result in a voiceless rather than a voiced affricate.

The common use of cluster reduction in aphasic patients with apraxia of speech is well documented in the literature (Blumstein, 1973). The interesting observation in the present study was the finding that when clusters were reduced the error segment could reflect an extraction of select features of one or more of the target elements, a phenomenon referred to in this study as 'feature merging'. Feature merging occurred in each case, but was found to be most common in Case 1 (the most severe case), and least common in Case 3 (the least severe case). This would seem to imply a simultaneous processing (decoding and encoding) of features comprising different phonemes. Further evidence is provided by the observation noted during testing that in each case occasional error utterances seemed to reflect the simultaneous production of two elements of a cluster. The intrusive schwa comprised the major part of vowel epenthesis, a process commonly reported in previous reports (Klich et al., 1979). Blumstein (1973) observed epenthesis of schwa and stop consonants, and she feels that these errors are often motivated by the particular environment in which they occur.

\section{Harmony Processes}

Harmony processes were generally common in the system of these cases. Assimilations occurred more commonly than metatheses and in each case regressive assimilations (anticipatory errors) outnumbered progressive assimilations (post-positioning errors) on both naming and spontaneous tasks. For A.M. and E.J. regressive assimilation occurred twice as frequently as progressive assimilation, while the difference was slightly narrower for F.T.

It may be observed in Table 3 that there was a striking predominance of alveolar assimilation on both tasks for all cases. There was a prevalence of alveolar and labial assimilation for A.M. and E.J. Velar and nasal assimilation occurred less commonly. Other assimilatory processes such as prevocalic voicing, initial and final consonant devoicing occurred, though less commonly in all cases. Assimilations took place not only with respect to syllables, phonemes or distinctive features within the boundary of a word, but also to those across word boundaries. Most errors occurred within a word. Metathesis occurred commonly in A.M.'s system, less commonly in F.T.'s system and was uncommon in E.J.'s system. A subcategory of metathesis was developed to indicate a reversal of individual features as opposed to reversal of an entire phoneme, which will be referred to as 'feature metathesis'. Feature metathesis comprised a major part of the total number of errors reflecting metathesis in the cases of A.M. and F.T., while only one instance of feature metathesis was noted on spontaneous tasks in the case of E.J. In F.T., for example, $63,64 \%$ and $75,00 \%$ of metathesis errors were seen to occur on naming and spontaneous tasks respectively.

The general trend that regressive assimilation occurred more commonly than progressive assimilation and that metathesis was less predominant, is consistent with previous findings (Blumstein, 1973; Itoh, Sasanuma and Ushijima, 1979). By contrast Sasanuma (1971) found metathesis to be more common than assimilation, but it is of interest to note that he found a similar occurrence of feature metathesis in his patients. The findings of feature metathesis contributes to the viewpoint discussed above that these patients may have simultaneous processing (decoding and encoding) of features comprising different phonemes. According to Itoh et al. (1979), the coarticulatory phenomenon in aphasic patients, especially anticipatory coarticulation, can be regarded as some manifestation of cortically generated motor programming. The analysis of data from a coarticulatory point of view thus seems to indicate that some 'future scanning' appears to be operating in these patients with apraxia of speech, so that for example, the articulatory gestures for the following segments are brought into the preceding segments. Anticipations, perseverations and transpositions of speech sounds occur in normal speakers and have been referred to as 'slips of the tongue' (Fromkin, 1971).

\section{Feature Contrast Processes}

Several processes governing the substitution of one sound for another were operating in each case. It may be observed in Table 3 that fronting and stopping were clearly the two feature contrast processes most commonly used, where fronting was more common than stopping. Fronting and stopping were predominant for A.M. and E.J., yet fronting alone was most common for F.T. Other processes operating for all cases were denasalization, nasal substitutions, velar substitutions, liquidation, interchange of $/ \mathbf{l} /$ and $/ \mathbf{r} /$, frication, affrication, vocalization and gliding. A review of the data showed that in the process of gliding, the substitution of / $w /$ was generally more common than $/ \mathrm{j} /$ in all cases.

These findings are consistent with previous research (Critchley, 1952; Blumstein, 1973). Specifically, the prevalence of stopping, in patients with apraxia of speech, has been highlighted (Klich et al., 1979). In support of the universality of language dissolution, Peuser and Fittschen (1977) found some similar phonological processes, such as stopping and denasalization, to be operating in a case of a Turkish aphasic, and thus feel that "Phenomic disorders due to aphasia seem to have a regular and universal character" (Peuser and Fittschen, 1977, p. 202). Thus in common with Blumstein (1973), it can be concluded that many of the error types found in these aphasic adults with apraxia of speech, do in fact reflect the natural phonological processes which operate in all languages. In this study the same phonological processes were seen to be operating for both singletons (CVC) and clusters (CCVC), providing evidence for the systematic government of articulation errors. Blumstein (1973) showed that phonological error patterns were systematic within groups and were similar across groups of aphasic adults. It might be valuable to-investigate further whether phonological errors in other aphasic types (with varied lesions) 
could be characterized by similar natural phonological processes as found for the Broca's aphasic cases of this study.

The data in this study refer to the speech samples of three adult cases. They therefore clearly cannot form the basis for any extensive comparison with the development of speech in children. However, the findings suggest that there are some differences between the phonological dissolution in these apraxic cases and phonological acquisition in the child, but that the general patterns in these adult cases resemble those used by children. The reader is referred to Wolk (1982b) for a further discussion.

During the course of eliciting phonological data it became clear that all cases tended to employ a number of different strategies to aid phonological production. Self-employed strategies were used on naming and spontaneous narrative tasks in their struggle with successive attempts towards the target utterance. The following strategies will be discussed below:

1. Revisualization of the written word.

2. Use of Semantic Associations.

3. Silent Articulations.

4. Reduced speech rate.

\section{Revisualization of the written word}

Case 1 (A.M.) and Case 2 (F.T.) were frequently able to evoke clear-cut mental images of the written words and could operate with these mental images, while they were completely unable to articulate them. A.M. could spell the appropriate letter(s) of a target word out aloud, although he could not produce them phonically, for example " $y$ " for "yacht", "g" for "frog" and "c,q" for "squirrel". It may be noted that he arbitrarily selected a letter from the initial or final word position. Furthermore, he spelled out aloud the letters "s", " $k$ ", " $y$ " for the word "sky", but could not articulate the word as a whole. He was often noted to recall the number of letters comprising a target word, such as "three letters" for "zoo". On one occasion A.M. was seen to perform the mechanical movements of writing with his fingers in an attempt to spell the word, i.e. "x, y, z . . zed" for "zoo". It thus appeared that he was mechanically converting sound sequences into graphic symbols.

F.T. was also noted to spell the words out aloud in order to facilitate articulatory production. The interesting feature noted in this case was that the articulatory error production often reflected a revisualization of the visual representation of the word (the graphic symbols) rather than the phonic representation (the acoustic image). For example $/ 1 \supset \mathrm{t} j \ldots \mathrm{j} \supset \mathrm{t} / /$ and $/ \mathrm{I} \supset \mathrm{t}\}$ ...t $\supset: /$ were successive attempts at the target word "yacht". It can be observed here that the error utterances show possible signs of interference from F.T.'s visual associations with spelling pronunciation variants. The finding that these cases recall printed letters in order to aid articulatory production is consistent with previous literature (Nebes, 1975).

\section{Use of Semantic Associations}

All cases were seen to employ a carrier phrase with semantic relevance in order to aid articulatory production. This tendency was the most prominant in F.T. Table 4 provides an example from the data for F.T., illustrating how he uses several semantic associations in order to recall the target item 'zebra'.
Here it can be seen that some basic features of the object to be named are distinguished. Buckingham and Rekart (1979) state that this necessitates a clear image of the object on the one hand, and a well-organized acoustic-phonologic structure of the appropriate name on the other. For further discussion, refer to Wolk (1982b).

Table 4 An example of the use of semantic associations to recall the target item 'zebra' by F.T.

\begin{tabular}{|c|c|}
\hline Target Word & $\begin{array}{l}\text { Error utterances in the } \\
\text { sequence as produced by } \mathrm{C2}\end{array}$ \\
\hline zebra & 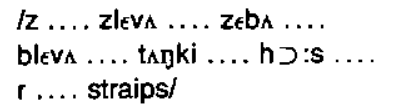 \\
\hline
\end{tabular}

\section{Silent Articulations}

It was observed during elicitation procedures that all cases used subvocal activity to aid articulatory production. This was in the form of continually moving articulatory structures groping to find correct postures.

On presentation of a stimulus item A.M. and E.J. were sometimes noted to monitor themselves silently using covert articulations prior to producing the word aloud. Similar behaviour was seen for F.T., although his covert articulations seemed to be combined with an audible whisper, and it was noted that for F.T. the labiodental fricative /f/ was commonly used during repeated trials of subvocal activity. An interesting observation was that F.T. often achieved correct articulation during whispering but not with voicing. This would suggest that one of the manifestations of the difficulty in this case with apraxia of speech, might be the co-ordination between articulatory and phono-respiratory mechanisms.

These findings are consistent with studies reported in the literature pertaining to both normal subjects and cases with apraxia of speech (McGuigan, 1970; Warren, 1977). McGuigan (1970) demonstrated that in normal adults internal verbal processes (rehearsal) are usually accompanied by small, covert movements of the lips, tongue and larynx which may be referred to as 'implicit speech'. McGuigan (1970) further states that as the performance of a task becomes more automatized, both the amplitude and the frequency of occurrence of these movements tend to decrease, which led to the suggestion that covert oral activity plays an important role in language. Nebes (1975) in common with Warren (1977) contends that patients with apraxia of speech have relatively intact implicit speech patterns. For the cases in this study, it is interesting to note that the amplitude and frequency of covert articulatory movements were significantly less in E.J. than in A.M. and F.T., suggesting that in the more severe cases of this study, automaticity of the articulatory movements was more impaired.

In an attempt to extrapolate from various proposals put forward by Nebes (1975), the following theoretical possibilities can be considered:

(a) Whether covert oral activity in these cases may in fact facilitate processing of articulatory images in the presence of possible auditory feedback disturbance, and 
(b) It may be that proprioceptive/kinaesthetic feedback from the muscles of articulation, which in these cases was felt to be disrupted (noted on oral stereognostic findings, which are not discussed in this paper), is an important factor in formulating an internal representation of the articulatory form.

\section{Reduced Speech Rate}

Finally a most significant observation was that all cases, particularly A.M., tended to reduce speech rate during their struggle with successive attempts towards the target utterance. This together with their deliberate syllabification of words was seen to aid correct production. This finding seems to highlight the importance of temporal sequencing in articulatory production and has obvious clinical implications.

\section{NEUROANATOMICAL FINDINGS}

The CT scans for each case are presented below (see figures $1,2$ and 3$)$.

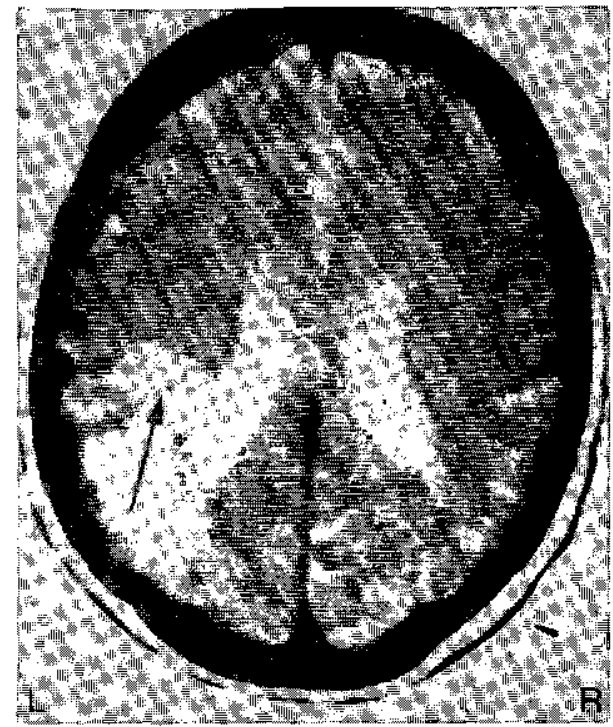

Figure 1 Case 1: A.M.'s CT scan showing cerebral infarction involving mainly the (L) parieto-occipital region and extending towards the island of Reil (insula) on the (L) side.

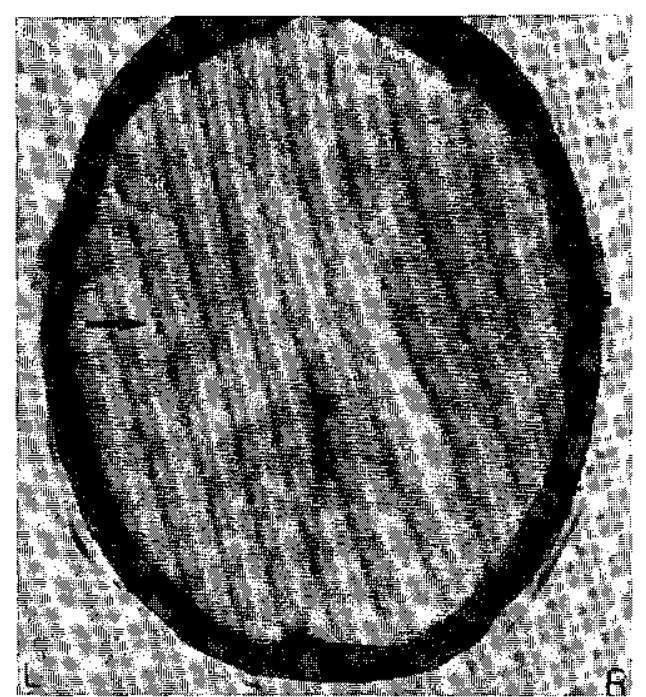

Figure 2 Case 2: F.T.'s CT scan showing cerebral infarcts in the (L) parieto-frontal region involving Broca's area and in the (A) parieto-occipital region.

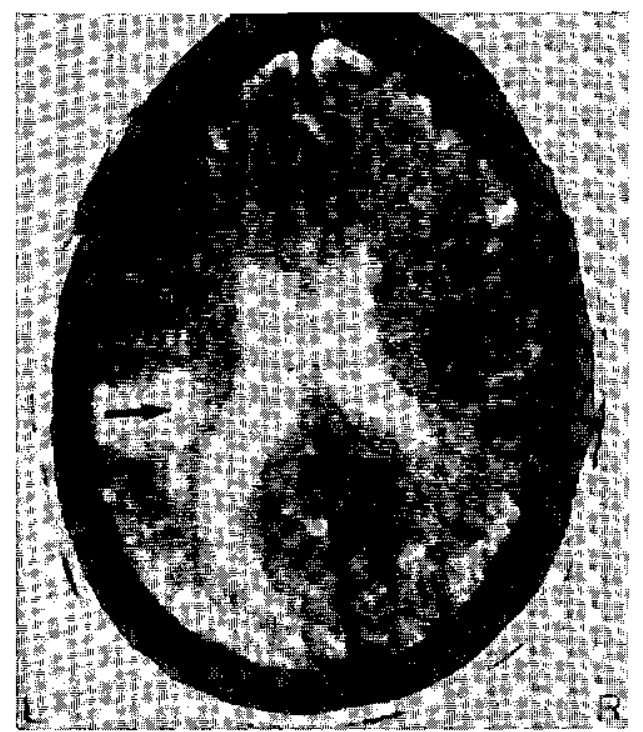

Figure 3 Case 3: E.J's CT scan showing cerebral infarction involving the (L) parietal region extending towards the vertox and Inferiorly to the (L) island of Reil (insula) and upper temporal lobe.

Table 5 Summary of CT Scan Results for all Cases

\begin{tabular}{|c|c|c|c|}
\hline & Case 1 - A.M. & Case 2 - F.T. & Case 3 - E.j. \\
\hline \multirow{5}{*}{$\begin{array}{l}\text { CT } \\
\text { SCAN }\end{array}$} & $\begin{array}{l}\text { - (L) parieto-occipital region, extending } \\
\text { towards the island of Reil (insula) on } \\
\text { the (L) side }\end{array}$ & $\begin{array}{l}\text { a) (L) parieto-frontal region including } \\
\text { Broca's area } \\
\text { b) (R) parieto-occipital region }\end{array}$ & \multirow{2}{*}{$\begin{array}{l}\text { - (L) parietal region, extending towards } \\
\text { the vertex, inferiorly to the island of } \\
\text { Reil (insula) and upper temporal } \\
\text { region on the (L) side } \\
\text { - generalized cerebral atrophy }\end{array}$} \\
\hline & & - moderate degree of cerebral atrophy & \\
\hline & $\begin{array}{l}\text { - asymmetry of lateral ventricles (left } \\
\text { larger than right) }\end{array}$ & $\begin{array}{l}\text { - asymmetry of lateral ventricles, } \\
\text { where }(L) \text { lateral ventricle is more } \\
\text { dilated than }(R) \text { ventricle } \\
\text { - widening of Sylvian fissure on (L) } \\
\text { side }\end{array}$ & $\begin{array}{l}\text { - generalized dilation of ventricular } \\
\text { system, and widening of sulci over } \\
\text { the vertex } \\
\text { - widening of Sylvian fissures bilate- } \\
\text { rally (left more than right) }\end{array}$ \\
\hline & $\begin{array}{l}\text { - no displacement of midline struc- } \\
\text { tures }\end{array}$ & $\begin{array}{l}\text { - no displacement of midline struc- } \\
\text { tures }\end{array}$ & $\begin{array}{l}\text { - no displacement of midline struc- } \\
\text { tures }\end{array}$ \\
\hline & $\begin{array}{l}\text { - no abnormal enhancement occurred } \\
\text { after contrast }\end{array}$ & $\begin{array}{l}\text { - some peripheral enhancement of } \\
\text { lesion in }(L) \text { Broca's area occurred } \\
\text { after contrast }\end{array}$ & $\begin{array}{l}\text { - no abnormal enhancement occurred } \\
\text { after contrast }\end{array}$ \\
\hline
\end{tabular}


The results will be discussed in relation to current research in the neuroanatomical correlates of language.

Each case discussed presents with the major neurological insult in the dominant (L) hemisphere. In the cases of A.M. and E.J., the major lesion is in the (L) hemisphere. In the case of F.T., the major lesion is in the (L) hemisphere with a minor lesion in the (R) hemisphere, which is said to have resulted from a mild transient $(R)$ hemispheric cerebral embolus suffered previously.

\section{... a major function of the left hemisphere is the control of changes in limb or articulatory posture, and its complex verbal and praxic functions are derived from such control. (Kimura, 1977 , p. 540)}

Here Kimura (1977) suggests that the (L) hemisphere contains a system specialized particularly for producing the correct articulatory posture, and consequently also for controlling the transition from one position to another. Halsey, Blauenstein, Wilson and Wills (1980) studied regional cerebral blood flow measurements in normal speakers and speakers with brain lesions. They found that in normal speakers during verbal activation, there were significant increases above rest level in the inferior frontal region, roughly corresponding to Broca's area. There were no significant differences between (L) and (R) hemisphere regions. According to Halsey et al . (1980), this relative symmetry of response suggests that probably relatively little intellectual effort is involved in ordinary speaking, and that the bilateral inferior frontal principle activation mainly reflects bilateral cortical control of the muscles of articulation. Further measurements were made during attempted speaking in patients with (L) and (R) hemisphere lesions. In the (L) hemisphere lesion group, the largest flow changes were in the inferior frontal and temporal regions bilaterally. The only interhemispheric significant difference was in the parietal region in the $(\mathrm{L})$ hemisphere lesion group. These findings are of particular interest in relation to the neurological findings of the cases in the present study. It may be observed that CT scans for each case revealed involvement of the parietal region.

Many years ago Liepman forecast that lesions permitting the appearance of apraxia ('facial apraxia' and 'apraxic dysarthria' now referred to as 'apraxia of speech') would be found in the parietal lobes, in the pre- and post-central gyri and the foot of the first two frontal gyri, with the subjacent part of the centrum semi-ovale, and the corpus callosum (Nathan, 1947). According to Buckingham (1979), the supramarginal gyrus is a crucial zone for the discussion of apraxia in general and of apraxia of speech. He states that:

Although it is a cortical area of the parietal lobe strategically located for the language zones, it is also anatomically quite near the arcuate fasciculus fibers traveling through opercular regions. (Buckingham, 1979, p. 212.)

Lebrun, Buyssens and Henneaux (1973) describe a single case with 'pure anarthria' who suffered a vascular accident in the (L) parietal lobe. The patient presented clinically with apraxia of speech, an absence of bucco-facial apraxia and no paralysis. In a more recent case study, investigations of an apraxic patient showed a lesion in the (L) parietal region (Di Simoni and Darley, 1977). Itoh, Sasánuma, Hirose, Yoshioka and Ushijima (1978) reported on CT scan findings in a patient with apraxia of speech, indicating an infarct involving the cortical surface near the anterior tip of the Sylvian fissure of the (L) hemisphere and the immediately subjacent white matter.

F.T.'s CT scan revealed a well marked lesion in Broca's area on the (L) side. Evidence in the literature suggests that a lesion in Broca's area will result in disintegration of skilled coordinated movements of the articulatory organs, referred to as motor apraxia of speech (Whitaker and Selnes, 1975; Mohr, Pessin, Finkelstein, Funkenstein, Duncan and Davis, 1978). It is probably not possible to identify a unitary aspect of speech with a delimited cortical area in the narrow sense, given the present state of our knowledge and methodology. While Broca's area is not felt to have a unitary function, there is recent evidence to support the general hypothesis that Broca's area is specialized for certain expressive (motor) components of language, particularly speech or articulatory parameters (Whitaker and Selnes, 1975). Goodglass and Geschwind (cited in Whitaker and Selnes, 1975, p. 92) have stated that:

... injuries in this area (Broca's Area) appear to implicate most directly but not exclusively the phonological and graphic aspects of language.

In a recent study, Ruff and Arbit (1981) describe a single case with 'aphemia' (apraxia of speech), whose CT scan reflects injury extending from Broca's area to the inferior left precentral gyrus. These writers suggest that the articulatory disturbance which they refer to as 'aphemia' may have resulted from disruption of the connection between Broca's area and the portion of the motor cortex that controls oral and pharyngeal muscles. Mohr et al. (1978) have found that when a lesion lies outside Broca's area and focally affects other adjacent sites in the operculum or insula, and even in a few instances apparently affects the deeper structures alone, the resulting syndromes are remarkably uniform, including dyspraxia and faint evidence of language disturbance. This provides some support for the findings in the present study, where a clearly identified lesion in Broca's area was observed on the CT scan for F.T., but not for A.M. and E.J.

The neuroanatomical findings in each case under study reflect lesions in the areas similar to those described in Broca's original patient. Broca, in describing the brain of his original aphasic patient, noted a large lesion encompassing the (L) insula, frontal, central and parietal operculum, and even extending into the adjacent inferior parietal region posterior to the Sylvian fissure (Mohr et al., 1978). He attributed this patient's aphasia to involvement of the frontal operculum, but not to the overall lesion. Thus we see his readiness to emphasize only a small, focal portion of the overall lesion. Mohr et al. (1978) feel that by modern standards, the initial physiologic basis for Broca's clinico-pathological correlations seems dubious, and yet, the concept of an aphasia produced by infarction of the Broca area has persisted. Recent literature thus highlights the constraints produced by dogmatic adherence to the traditional formulation of the syndrome referred to as Broca's aphasia, resulting from infarction of the Broca's area. It is currently felt that the syndrome arises from a considerably larger brain injury in the Sylvian region, that encompasses most of the operculum, insula and subjacent white matter in the territory of the middle cerebral artery scrving the dominant cerebral hemisphere; thus far exceeding Broca's area. This in fact conforms more to the 
large zone of damaged brain actually present in Broca's original cases (Roch-Lecours and Lhermitte, 1976). Mohr et al. (1978) together with Whitaker and Selnes (1975) contend that Broca's aphasia emerges as a residuum of a larger infarct which initially produces global aphasia. They suggest that there is a gradual emergence of stereotypes, agrammatism and protracted apraxia of speech which evolve slowly towards the long-standing deficit profile of Broca's aphasia.

\section{CONCLUSION}

From the discussion above, it is concluded that there is a certain lawfulness to the apraxic impairment in these adult aphasic patients. Articulation errors on single consonants and consonant clusters were characterized by systematic rule-governed behaviour. In each case, it was possible to trace underlying phonological processes which fit into strategy groups operationalizing particular phonetic preferences. The major process groups included a tendency for less complex syllable structures to replace more complex ones, a tendency towards phonetic symmetry and a tendency for errors to result from a lack of feature contrasts. In syllable structure processes, cluster reduction, deletion of final consonants and weak syllable deletion were most common. Harmony processes were generally common, where assimilations occurred more frequently than metatheses and regressive assimilations outnumbered progressive assimilations. In feature contrast processes, fronting and stopping were clearly most common. Similar error trends occurred on both singletons and clusters for all cases.

Analysis from a coarticulatory point of view indicated that some 'future scanning' appeared to be operating in these patients with apraxia of speech, resulting in assimilatory processes, feature merging and feature metathesis. It is thus argued that the impairment in these cases may not be confined to the motor aspects of speech, but probably extends into the linguistic spheres as well. This suggests that descriptions of apraxia of speech and clinical treatment regimes should perhaps consider both linguistic and articulatory variables.

All cases employed a number of strategies to aid phonological production. This has several theoretical implications. In particular, revisualization of the written word and the use of silent articulations may indicate the preservation of relatively intact implicit speech patterns in these cases. All cases made several errors which were semantically related to the target word, yet fully explicable phonologically. This, combined with the fact that a carrier phrase with semantic relevance was often employed to aid phonological production, would suggest simultaneous semantic and phonological processing in these cases. This highlights direction for further research into the simultaneous processing or overlap between the levels of language in the aphasic patient. Reduced speech rate was seen to facilitate improved phonological production, which may suggest a disruption in timing for these cases.

The neuroanatomical findings suggest that apraxia of speech in these cases may result from some synergistic interaction between several areas of the brain rather than a specific localized area. This is in agreement with the view proposed by Roch-Lecours and Lhermitte (1976) who suggest that particular language functions may be the result of an interaction of the entire opercular and insula regions. The findings indicate that apraxia of speech for these subjects does not appear to exist as a separate entity, but rather as a part of the total aphasic breakdown. Parietal involvement suggests that enhanced kinaesthetic awareness and tactile discrimination of speech sounds should perhaps be more emphasized in therapy than has previously been considered. The fact that the brain lesion in each case was more extensive than would be expected in the traditional concept of a focal lesion in Broca's area, would seem to suggest an orientation away from rigid diagnosic differentiation between Broca and Wernicke aphasic types. In this way, the speech pathologist might take cognisance of symptoms which could otherwise be overlooked.

A phonological process analysis may form the basis for therapy by providing a way of describing the adult aphasic's phonological system as an entity, and allowing the clinician to isolate individual phonological processes contributing to unintelligibility. Entire processes may thus be the focus of therapy rather than isolated sounds. Clinically, it may be useful to explore the value of graphic symbols, covert articulatory movements and enhanced kinaesthetic awareness in the management of patients with apraxia of speech. In addition, treatment procedures involving rhythm, rate and syllable timing might be fruitful for future research.

It is hoped that these findings will stimulate future investigations to improve both diagnostic and therapeutic efficacy and contribute to the endless search in understanding one of the most complex disorders of the human brain.

\section{ACKNOWLEDGEMENTS}

The writer wishes to offer her sincere thanks to Professor M. L. Aron, Head of the Department of Speech Pathology and Audiology and Dr. C. Penn, Senior Lecturer in the Department of Speech Pathology and Audiology, University of the Witwatersrand, for their guidance and support in carrying out this research. For financial assistance, the writer is grateful to the Human Sciences Research Council and the Witwatersrand University Senior Bursary Fund.

\section{REFERENCES}

Blumstein, S.E. A Phonological Investigation of Aphasic Speech. Brown University and Aphasia Research Centre, Boston, The Hague: Mouton and Co., 1973.

Bowman, C. A. A Process Analysis of Verbal Apraxia. Paper presented at the Annual American Speech-LanguageHearing Association (ASHA) Convention, Toronto, Canada, November, 1982.

Buckingham, H.W. Explanation in Apraxia with Consequences for the Concept of Apraxia of Speech. Brain Lang., $1979,8,202-226$.

Buckingham, H. W. \& Rekart, D. M. Semantic Paraphasia. J. Commun. Disord., 1979, 12(3), 197-209.

Cohen, J.A., Gelfer, C.E. and Sweet, R.D. NeurologicNeurosurgical Notes: Thalamic Infarction producing Aphasia. Mt. Sinai. J. Med. (NY)., 47(4), 398-404, 1980.

Critchley, M. Articulatory Defects in Aphasia. J. Laryngol. Otol., 1952, 66, 1-17.

Deal, J. L. and Darley, F. L. The Influence of Linguistic and Situational Variables on Phonemic Accuracy in Apraxia of Speech, J. Speech Hear. Res., 1972, 15(3), 639-653. 
De Renzi, E. and Faglioni, P. Normative Data and Screening Power of a Shortened Version of the Token Test. Cortex, 1978, 14(1), 4l-49.

Di Simoni, F. G. and Darley, F. L. Effect on Phoneme Duration Control of Three Utterance-length Conditions in an Apractic Patient. J. Speech Hear. Dis., 1977, 42, 257-264.

Fromkin, V. A. The Non-anomalous Nature of Anomalous Utterances. Language, 1971, 47, 27-52.

Goldman, R., Fristoe, M. S. and Woodcock, R. W. GoldmanFristoe Test of Auditory Discrimination. Minnesota: American Guidance Service, Inc., 1970.

Goodglass, H. and Kaplan, E. The Assessment of Aphasia and Related Disorders. Boston Veterans Administration Hospital and Aphasia Research Centre, Department of Neurology, Boston University, 1972.

Halsey, J. H., Blauenstein, U. W., Wilson, E. M. \& Wills, E. L. Brain Activation in the Presence of Brain Damage. Brain Lang., 1980, 9(1), 47-60.

Ingram, D. Phonological Disability in Children. Studies in language Rehabilitation and Remediation 2. Department of Linguistics, University of British Columbia: Edward Amold, Ltd., 1976.

Ingram, D. Procedures for the Phonological Analysis of Children's Language. Baltimore: University Park Press, 1981.

Itoh, M., Sasanuma, S., Hirose, H., Yoshioka, H. and Ushijima, T. Articulatory Dynamics in a Patient with Apraxia of Speech: X-ray Microbeam Observation. Annu. Bull. RILP., 1978, No. 12, 87-96.

Itoh, M., Sasanuma, S. and Ushijima, T. Velar movements during Speech in a Patient with Apraxia of Speech. Brain Lang., 1979, 7, 227-239.

Kimura, D. Acquisition of a Motor Skill after Left Hemisphere Damage. Brain, 1977, 100, 527-542.

Klich, R. J., Ireland, J. V. and Weidner, W. E. Articulatory and Phonological Aspects of Consonant Substitutions in Apraxia of Speech. Cortex, 1979, 15,(3) 341-470.

Lebrun,'Y., Buyssens, E. \& Henneaux, J. Phonetic Aspects of Anarthria. Cortex, 1973, 9, 126-135.

Martin, A. D. Some Objections to the Term 'Apraxia of Speech'. J. Speech Hear. Dis., 1974, 39(1), 53-64.

Martin, A. D. and Rigrodsky, S. An Investigation of Phonological Impairment in Aphasia, part 1: Cortex, 1974(a), 10(4) 317-328.

Martin, A. D. and Rigrodsky, S. An Investigation of Phonological Impairment in Aphasia, Part 2: Distinctive Feature
Analysis of Phonemic Commutation Errors in Aphasia. Cortex, 1974(b), 1064), 329-346.

McGuigan, F. J. Covert Oral Behaviour during the Silent Performance of Language Tasks. Psychol. Bull., 1970, 74, 309-326.

Mohr, J. P., Pessin, M. S., Finkelstein, S., Funkenstein, H. H., Duncan, G. W. and Davis, K. R. Broca Aphasia: Pathologic and Clinical. Neurology, 1978, 28, 311-324.

Moore, W. M., Rosenbek, J. C. and La Pointe, L. L. Assessment of Oral Apraxia in Brain-Injured Adults. Proceedings of Clinical Aphasiology Conference, Portland, Oregon, May, 1976.

Nathan, P. W. Facial Apraxia and Apraxic Dysarthria. Brain, 19487, 70, 449-478.

Nebes, R. D. The Nature of Internal Speech in a Patient with Aphemia. Brain. Lang., 1975, 2, 489-497.

Peuser, G. and Fittschen, M. On the Universality of Language Dissolution: The Case of a Turkish Aphasic. Brain. lang., 1977, 4, 196-207.

Roch-Lecours, H. and Lhermitte, F. The Pure Form of the Phonetic Disintegration Syndrome (pure anarthria). Brain. Lang., 1976, 3, 88-113.

Ruff, R. L. and Arbit, E. Aphemia resulting from a left Frontal Hematoma. Neurology, 1981, 31, 353-356.

Sarno, M. T. and Levita, E. Natural Course of Recovery in Severe Aphasia. Arch. Phys. Rehabil., 1971, 52, 175-178.

Sasanuma, S. Speech Characteristics of a Patient with Apraxia of Speech. Section of Communication Research, Department of Rehabilitation Medicine. Tokyo Metropolitan Institute of Gerontology, Tokyo, Japan. 1971.

Warren, R. L. Rehearsal of Naming in 'Apraxia of Speech'. Proceedings of Clinical Aphasiology Conference, 1977. 80-90.

Weiner, F. F. Phonological Process Analysis. Baltimore: University Park Press, 1979.

Whitaker, H. A. and Selnes, O. A. Broca's Area: A Problem in Language-Brain Relationships. Linguistics An International Review, 154/155, June 15, 1975, 91-101.

Wolk, L. Phonological Impairment in Aphasia. Paper presented at the Annual American Speech-Language-Hearing Association (ASHA) Convention, Toronto, Canada, November, 1982(a).

Wolk, L. Phonological Impairment in Aphasia. Unpublished dissertation submitted to the Department of Speech Pathology and Audiology, University of the Witwatersrand, Johannesburg, South Africa, 1982(b). 


\section{GSI 28 Auto Tymp}

The GSI 28 AUTO TYMP provides testing capability for tympanometry, ipsilateral and contralateral acoustic reflex testing and screening audiometry. Selection of test sequence is as simple as pressing a button! The Auto Tymp is lightweight and compact so it can be easily moved from one location to another. An optional carrying case is available if more portability is required.
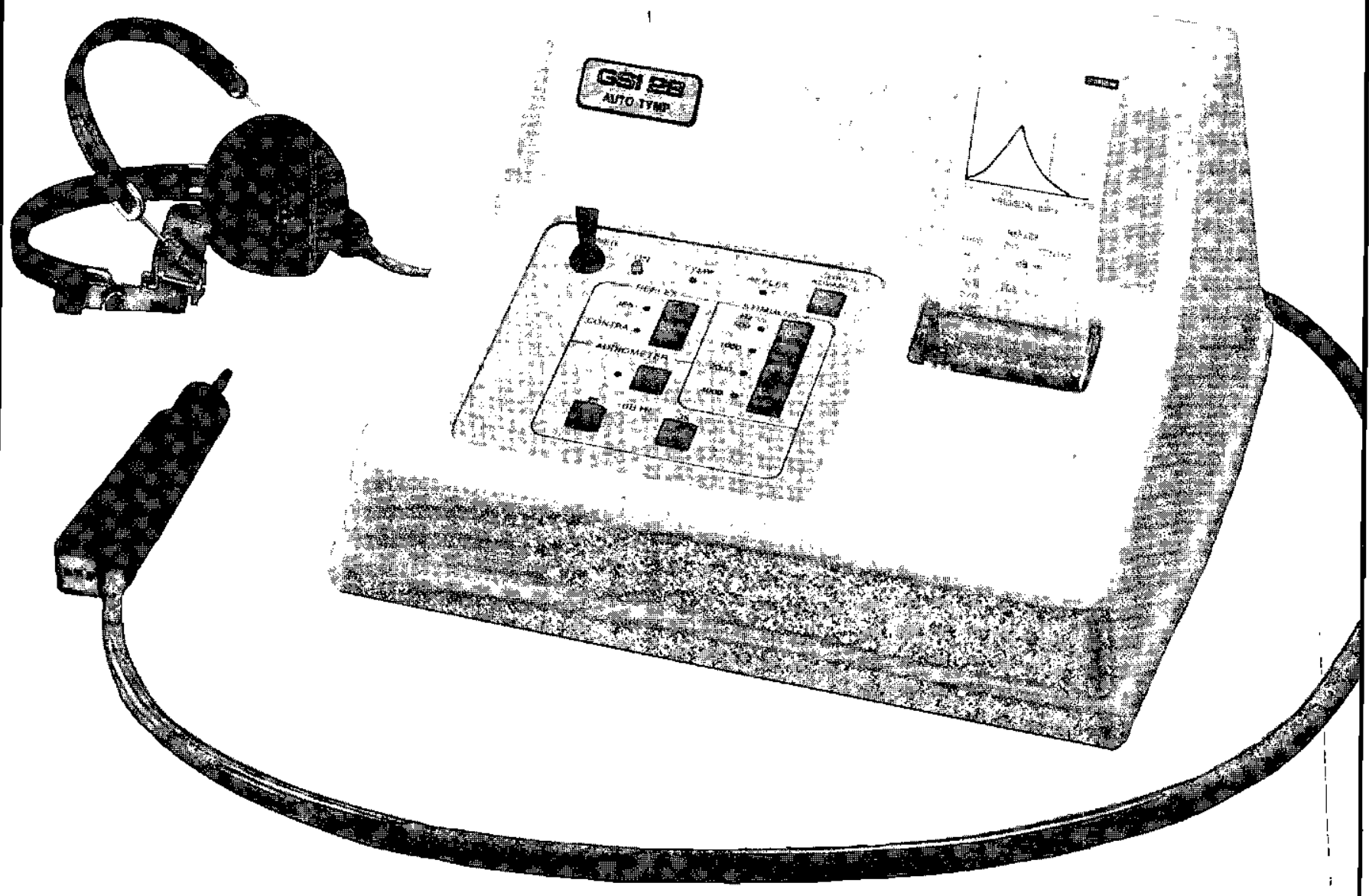

The Needier Westdene Organisation (Pty) Limited

In association with / in medewerking met HEARING AND ACOUSTIC INSTRUMENTS (PTY) LTD LEWIS'S HEARING CENTRE (PTY) LTD ENGINEERED ACOUSTIC PRODUCTS NOISE CONTROL

Needler Westdene House, 33 Durham St., Raedene, Johannesburg 2192, South Africa. Telex: 4-25028.
P.O. Box 28975, Sandringham 2131, South Africa. Tel: (011) 640-5017. Cables: Needlerog. 